\title{
ARTICULOS LIBRES
}

\section{¿ INVENTORES, APÓSTOLES, IDOLOS O CACIQUES? UNA APROXIMACIÓN A LA PROBLEMAIIZACIÓN DEL “LIDER” EN LOS ALBORES DEL PENSAMIENTO SOCIOLOOGICO Y PSICOSOCIAL"}

INVENTORS, APOSTILES, IDOLS OR CHIIEFTIINS? AN APPROACH TO THE PROBLEMAIIZATION OF THE "LEADER" AT THE DAWN OF SOCIOLOGICAL AND PSYCHO-SOCIAL THOUGHT

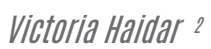

RESUMEN A partir de la relectura de un corpus de textos de Gabriel Tarde, Gustave Le Bon, José María Ramos Mejia y Carlos Augusto Bunge, realizada desde la perspectiva de la simultaneidad, en el artículo se caracterizan y comparan los modos en que se pensó el problema de la jefatura en la sociología y la psicología social de fines del siglo XIX y principios del XX. Luego de reponer, en sus rasgos principales, las encrucijadas epocales y teóricas con las cuales se vinculan los textos considerados, el trabajo se focaliza sobre las figuras de los lideres que entendidos como "inventores", "apóstoles del orden", "idolos de masas" y "caciques" emergen, respectivamente, de las elaboraciones de los autores antes mencionados. De la mano de la exploración de tales figuras se identifica un conjunto de dimensiones analiticas que puede nutrir la realización de investigaciones futuras acerca del liderazgo, tanto de corte teórico como genealógico.

Palabras clave: Lider, pensamiento psico-social, historia, simultaneidad.

ABSTRACT Starting from the rereading of a corpus of texts by Gabriel Tarde, Gustave Le Bon, José María Ramos Mejía and Carlos Augusto Bunge, carried out from the perspective of simultaneity, the article characterizes and compares the ways in which the problema of leadership was thought of in the sociology an social psychology of the late nineteenth and early twentith centuries. After replenishing, on its main features, the epochal and theoretical crossroads with which the texts considered are linked, the work focuses on the figures of the leaders who understood as "inventors", "apostles of order", "masses idols" and "chieftains", emerge, respectively, from the elaborations of the aforementioned authors. Hand in hand with the exploration of such figures, a set of analytical dimensions are identified that can nurture the carrying out of future theoretical and genealogical investigations.

Key words: Leader, psycho-social thought, history, simultaneity.

1 Artículo recibido 9 de julio de 2020. Aprobado 30 de octubre 2020.

\footnotetext{
${ }^{2}$ Investigadora Adjunta del Conicet-Centro de Investi-
} gaciones de la FCJS/UNL.vhaidar@fcjs.unl.edu.ar

\section{INTRODUCCIÓN}

¿Qué se espera de los líderes? ¿Qué funciones se les atribuyen? ¿Qué palabras y figuras se utilizan para aludir a aquellos que ejercen roles de conducción? Tales preguntas, en sus diferentes acentuaciones, constituyen algunas de las formulaciones bajo las que se articula la demanda social de líderes. Con esta última expresión nos referimos al deseo de que otro dirija, comande, guie, oriente, etc., nuestras acciones.

En sociedades como las nuestras, en las que vivir autónoma y "emprendedoramente" se ha transformado en un mandato, y en las que ningún hombre o mujer goza de automática e indiscutible superioridad, tal demanda puede considerarse inactual.

Sin embargo, una serie de datos de la realidad, como ser el resurgimiento mundial de los populismos, la abrumadora presencia que tienen los manuales de liderazgo en el mercado editorial, no menos que el auge del couching, parece contradecir tal impresión. Lejos de haber desaparecido de nuestro paisaje social y existencial, el deseo de conducir y de ser conducidos resulta sostenido y estimulado, en lo cotidiano, por una serie de racionalidades y tecnologías que provienen tanto de las ciencias de la empresa como de cuerpos de pensamiento y prácticas ligados al desarrollo personal y la espiritualidad.

En tiempos de "personalización de la política" (D'Alessandro, 2004; Blondel y Thiébault, 2010), no solo la novedosa figura del "director de equipos" aprovecha los servicios de consultores y consejeros psicológicos. También los líderes de los nuevos populismos apelan al marketing para reforzar los rendimientos que extraen de la posesión del carisma. Y otro tanto sucede con el "director de proyectos"; prototipo contemporáneo gestado al calor del couching, la literatura de autoayuda y las variadas experticias que se aplican a mejorar la performance gerencial.

Considerada en forma global, la problematización actual del liderazgo resulta irrigada por discursos que giran en torno a la figura del "empresario" e interpelan a los individuos a actuar en formas que promuevan el logro del éxito en los variados proyectos (profesionales, comunitarios, deportivos, personales) que comandan. 
De Prácticas y discursos

Universidad Nacional del Nordeste

Centro de Estudios Sociales

Año 9, Número 14, 2020, Octubre

ISSN 2250-6942

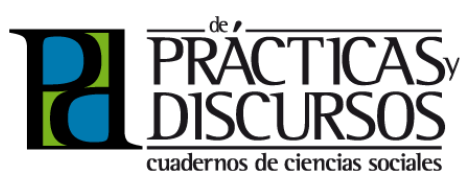

3 Sobre el modo en que "lo social" se problematizó en la Argentina, pueden consultarse los trabajos en clave genealógica realizados por Haidar (2008) y Aguilar (2013).

${ }^{4}$ Gabriel Tarde (1843-1904) nació en el seno de una familia nobiliaria vinculada al ejercicio de la justicia. Tras graduarse en derecho, comenzó una carrera en la magistratura judicial, lo cual no fue obstáculo para la generación de una prolífica y multifacética obra que incluye aportes en el ámbito de la sociología, la filosofía, la criminología, etc. En vida gozó de un amplio reconocimiento que se extendió por fuera de las fronteras de Francia, pero que decayó abruptamente tras su muerte. El olvido al que fue relegado su pensamiento se revirtió, en los últimos años, de la mano de la relectura y reedición de sus textos.

${ }^{5}$ Habiendo obtenido el grado de médico, Gustave Le Bon (1843-1931) abandonó pronto la práctica de la profesión para dedicarse a la divulgación científica. Luego de incursionar en el campo de la física y de escribir, entre otros tópicos, sobre la historia de diversas civilizaciones, se volcó a la psicología social. La publicación de sus reflexiones en torno de la psicología de los pueblos (1894) y de las masas (1895) le franquearon un lugar entre los intelectuales y políticos franceses más reputados, convirtiéndolo en un autor de renombre internacional.

${ }^{6}$ Ramos Mejía (1849-1914) procedía de una familia tradicional argentina. Graduado como médico, tuvo una participación activa en la política argentina que incluyó el desempeño de varios cargos públicos. Entre otros, en 1882 fue nombrado director de la Asistencia Pública, y entre 1908 y 1912 estuvo a la cabeza del Consejo Nacional de Educación. Considerado como uno de los autores emblemáticos del movimiento positivista argentino, sus escritos, que combinan de manera ecléctica puntos de vista médico-biológicos, históricos y sociológicos, se ocupan de problematizar la "locura" (religiosa y política), el rol de las multitudes en la historia política argentina y el empleo de la simulación como instrumento de ascenso social.

7 Oriundo de una familia tradicional de ascendencia alemana, en 1897 Bunge (1875-1918) se graduó como abogado, llegando a ocupar el cargo de fiscal en el Poder Judicial. Profesor universitario, además del derecho, cultivó la pedagogía, la filosofía y la sociología, siendo precursor del pensamiento psicosocial en la Argentina. En 1899 integró junto al ministro de educación Osvaldo Magnasco la comitiva que fue a Europa con el objetivo de conocer su sistema educativo. Inscripto, al igual que Ramos Mejía, en el paradigma positivista, fue considerado defensor de las proposiciones del darwinismo social en la Argentina.
Sin embargo, ello no siempre fue así. Entre fines del siglo XIX y principios del XX, un discurso de ese estilo fluyó, en cambio, del caudaloso manantial de estudios científicos, programas, ensayos de interpretación, etc., que se dedicaron, tanto en los paises del Norte como del Sur, a problematizar lo "social" (Donzelot, 2007; Osborne y Rose, 1997)3.

En este artículo presentamos los perfiles de líderes que, dentro de ese vasto universo, articularon un conjunto de escritos que se inscribe en el ámbito de la sociología y la psicología social: Las leyes de la imitación (1890) de Gabriel Tarde ${ }^{4}$, Psicología de las masas (1895) de Gustave Le Bon ${ }^{5}$, Las multitudes argentinas (1899) y Los simuladores de talento (1904) de José María Ramos Mejía ${ }^{6}$ y Nuestra América (1903) de Carlos Octavio Bunge?.

Tal como explicamos en el primer apartado del trabajo, los escritos de Tarde, Le Bon, Ramos Mejía y Bunge encontraron inspiración en una trama común de encrucijadas epocales y teóricas. Engarzadas, sea en una teoría sociológica impregnada de psicología, sea en ensayos de corte psicosocial que pretendian diagnosticar, explicar o interpretar, según los casos, la situación de la "época" o la "realidad nacional" en la que aparecieron, de tal dominio discursivo surge un conjunto de formulaciones que delinea cuatro perfiles diferentes de conductores.

"Inventores" de creencias, movimientos artísticos, doctrinas religiosas, tecnologías de producción, etc., tanto como "apóstoles de lo nuevo", tal es el papel que Gabriel Tarde les confirió en su edificio teórico. Según argumentaremos en el segundo apartado del trabajo, al introducir y propagar innovaciones destinadas a resolver problemas, los líderes coadyuvaban tanto a renovar las ideas y prácticas establecidas como a incrementar la armonía social.

Al igual que el apóstol comprometido con la divulgación de novedades, el jefe de las multitudes que Le Bon deseaba ver surgir entre las elites de su época tenía, como explicaremos en el tercer apartado, una misión: estaba llamado a conjurar el peligro de la decadencia de la civilización occidental, pregonando, en su carácter de "apóstol del orden", un antiguo saber.

Por su parte, en el texto que dedicó a reescribir la historia de la independencia argentina, Ramos Mejía hizo de los variopintos meneurs que jalonan tal desarrollo (principiando por los brujos y nigromantes de los tiempos de la colonia hasta llegar a los caudillos de la época de anarquía), no más que los "ídolos" creados a partir del colosal poder deformante que atribuye a la imagina- 
De Prácticas y discursos

Universidad Nacional del Nordeste

Centro de Estudios Sociales

Año 9, Número 14, 2020, Octubre

ISSN 2250-6942
¿ Inventores, apóstoles, ídolos o caciques? Una aproximación a la problematización del "Iíder" en los albores del pensamiento sociológico y psicosocial

Inventors, apostles, idols or chieftains? An approach to the problematization of the "leader" at the dawn of sociological and psycho-social thought

ción de las masas, verdaderas protagonistas de la historia.

Como desarrollaremos en el cuarto apartado, en un ensayo barroco, que puede leerse como una reacción frente al ascenso de las clases plebeyas a los lugares de poder otrora reservados a la casta de "señores" a la que el propio autor pertenecía (González, 2000), Ramos Mejía se focaliza en el análisis psicosocial de aquellas personalidades que, por su plasticidad, eran propensas a encabezar los movimientos de masas, y de las cuales pensaba que "simulaban talento".

Ya en Nuestra América, publicado en 1903, Carlos Octavio Bunge se refirió al engaño y la falsificación como formas a las que el "cacique gaucho" apelaba para fascinar a las masas en el contexto de lo que el autor llamó la "política criolla": una constelación de prácticas determinada, según explicaremos en el quinto punto del trabajo, por el "carácter de los argentinos", que encontraba en los vínculos de compadrazgo originados en el ritual católico del bautismo, una de sus raíces.

Así, a lo largo del artículo nos ocuparemos de caracterizar y poner en diálogo los perfiles de líderes a los que antes nos referimos, poniendo especial hincapié, según explicamos en el apartado siguiente, en el "carácter simultáneo" (Bialakowsky, 2018; Bialakowsky y Blanco, 2019) de los desarrollos a partir de los cuales los autores del Norte y del Sur les dieron forma. De la multiplicidad de aristas desde las que tal problemática puede ser escudriñada, aquí priorizamos la consideración de: los registros de análisis a partir de los cuales Tarde, Le Bon, Ramos Mejía y Bunge abordaron la figura del jefe; los términos y metáforas a los que apelaron para ponerlo en discurso; las funciones que, según pensaron, los mismos ejercían o estaban llamados a cumplir y el modo en que, en los textos, la cuestión de la jefatura se vincula a la pregunta relativa a la reconfiguración de las jerarquías en las sociedades democráticas. El artículo se cierra con unas breves reflexiones.

\section{LOS TEXTOS EN ALGUNOS DE SUS CONTEXTOS}

El repertorio de líderes que aquí presentamos constituye un efecto de lectura, entre otros posibles, de un corpus formado por un conjunto de secuencias discursivas extraídas de una selección de textos delimitados en función de dos criterios.

Uno es de orden disciplinar. Los materiales con los que traba- 
De Prácticas y discursos

Universidad Nacional del Nordeste

Centro de Estudios Sociales

Año 9, Número 14, 2020, Octubre

ISSN 2250-6942

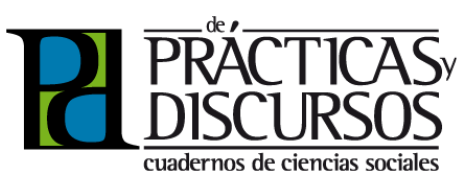

\begin{abstract}
${ }^{8}$ Hacia fines del siglo XIX, la psicología social no gozaba de autonomía. Sin embargo, como destaca Apfelbaum (1988), desde distintos paises y de manera casi simultánea, un conjunto de autores (que incluía tanto a los franceses Tarde y Le Bon como al argentino Bunge) produjo, por esa época, desarrollos de corte psicosocial.
\end{abstract}

\begin{abstract}
${ }^{9}$ Sobre la imbricación del saber clínico y el saber literario en la producción de Ramos Mejía, véase Von Stecher (2014).

${ }^{10}$ Como advierte Alejandra Mailhe (2016:21), en el prólogo de Nuestra América, Bunge apela a tópicos clisés del modernismo para teatralizar la crisis del sujeto decadente que da origen a la indagación sociológica del libro; procurando, con ello, ganar la atención del incipiente lectorado de masas.
\end{abstract}

11 En lugar de hacer surgir a la sociología de una ruptura radical con la filosofía, como hizo Émile Durkheim, Tarde apostó a buscar en ella los principios ontológicos que permitan sostener un "punto de vista sociológico universal” (Blanco, 2016). jamos se erigen en el espacio anfibio de enunciación que, hacia fines del siglo XIX, formaban, al entrecruzarse, las perspectivas de la sociología (ciencia que tanto en Francia como en Argentina estaba, por entonces, en pleno proceso de institucionalización) y la psicología social (cuerpo de saber que, en cambio, conquistó su autonomía recién a mediados del siglo XX) ${ }^{8}$.

Si bien aquí privilegiamos tal combinación, es preciso destacar que, para referirse a los conductores, los autores que revisitamos se sirvieron, asimismo, de otros saberes y materiales. Así, la cuestión de la jefatura aparece trabajada, en los libros de Ramos Mejía y Bunge, desde una perspectiva psicosociológica que se nutre, en todo momento, de materiales históricos. Y, sin perjuicio de la pretensión cientificista que imprimieron a sus proyectos, ambos autores abrevaron en la literatura como fuente de recursos que le servirian, al primero, para imprimir a su escritura un estilo elegante y sólido ${ }^{9} y$, al segundo, para amplificar el impacto de su intervención ${ }^{10}$.

Asimismo, no puede pasarse por alto el modo en que tanto el oficio del articulista político como el estilo enunciativo que distingue a la literatura de consejos al príncipe se cuela en la Psicología de las masas de Gustave Le Bon; ni la envergadura filosófica que adquieren, en la sociología de Tarde, las nociones de invención e imitación, las cuales brindan el marco en el que se inscriben las formulaciones que conciernen a los conductores ${ }^{11}$.

El segundo de los criterios que empleamos para seleccionar y agrupar los materiales es de orden temporal: trabajamos con formulaciones procedentes de textos publicados en un mismo lapso. Así, al constituir nuestro corpus a partir de secuencias discursivas que coexisten, optamos por una estrategia de lectura distinta a aquella que ponen en movimiento las teorias de la recepción, las que, aun reconociendo la creatividad que esta última implica, fundan la interpretación de un texto en la adopción "local" de ideas producidas en otras latitudes.

Mientras las lecturas que acentúan la cuestión de la recepción entienden la temporalidad en términos de "sucesión", esto es, parten del supuesto de que hay textos que "anteceden" a otros, la lectura que aqui proponemos trabaja sobre la temporalidad entendida en términos de "simultaneidad"; es decir, pone en conexión los textos a partir del énfasis en el carácter coetáneo de su producción. Ello permite echar luz sobre el abanico más amplio de conversaciones que los escri- 
De Prácticas y discursos

Universidad Nacional del Nordeste

Centro de Estudios Sociales

Año 9, Número 14, 2020, Octubre

ISSN 2250-6942
¿ Inventores, apóstoles, ídolos o caciques? Una aproximación a la problematización del "Iíder" en los albores del pensamiento sociológico y psicosocial

Inventors, apostles, idols or chieftains? An approach to the problematization of the "leader" at the dawn of sociological and psycho-social thought

\footnotetext{
${ }^{12}$ Un mayor detalle del referido abordaje simultáneo movilizado para comparar, específicamente, las sociologías argentina y francesa durante sus momentos fundacionales, se encuentra en Bialakowsky y Blanco (2019).
}

tos que aquí revisitamos mantienen entre sí, y que incluyen tanto intercambios "locales" como "transoceánicos ${ }^{12 " . ~}$

Es que, sin perjuicio del carácter asimétrico de los espacios sociopolíticos de los que proceden, lo escritos que conforman nuestro corpus fueron producidos en una misma coyuntura histórica, constituyendo, cada uno de ellos, una respuesta a una trama "común" de encrucijadas epocales y teóricas que declina, ciertamente, de manera diferente en Francia y en Argentina; explicándose tal bifurcación por incidencia que en la dinámica de retroalimentación entre "problemas" y "marcos interpretativos", a partir de la que se constituyen los objetos de estudio, desempeñan las circunstancias, querellas y lecturas locales (Bialakowsky y Blanco, 2019).

Así, los desarrollos que en las obras de los cuatro autores considerados delinean unos ciertos perfiles de líderes, partieron de las perplejidades, temores, inquietudes y desafíos que generaron, en las elites, algunos de los procesos que conmovieron a las sociedades modernas en la última década del siglo XIX.

Tanto Las leyes de la imitación como Psicología de las masas se inscriben en el contexto de la denominada Tercera República, escenario político signado por las experiencias inmediatamente anteriores de la Comuna de París y la derrota en la guerra franco-prusiana, que dejaron como saldo el temor a la violencia política y la inestabilidad institucional. El ciclo de revoluciones (1830, 1848 y 1871) que atravesó Francia hacia mediados del siglo XIX, no menos que la proliferación de huelgas, alimentaron en las elites el temor de un resurgimiento de sentimientos revolucionarios "radicales" (Terán, 2010).

El creciente protagonismo que, según dejaron de manifiesto tales acontecimientos, habian asumido las "multitudes", explica que las mismas comenzaran a recortarse como objeto de análisis político y científico. Para la configuración de tal problemática resultó clave la publicación, en 1895, de Psicología de las masas. Si bien en su texto Le Bon articuló y sintetizó varias de las reflexiones que sobre tal temática venían produciéndose, desde 1870, en el ámbito de la criminología, la historia y la psicología, el mismo se convirtió en un verdadero manifiesto fundante de aquel dominio de análisis científico que, desde entonces, se conoce como "psicología de las masas" (Moscovici, 1985; Borch, 2012). Percibidos como peligrosos o directamente criminales, los comportamientos de las muchedumbres funcionaron como disparadores de 
De Prácticas y discursos

Universidad Nacional del Nordeste

Centro de Estudios Sociales

Año 9, Número 14, 2020, Octubre

ISSN 2250-6942

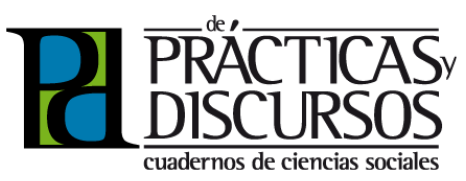

${ }^{13}$ Los escritos que Tarde (2015a, 2015b) dedicó al tema de los crímenes de las muchedumbres no delinean algo así como un "perfil" o "modelo" de líder, razón por el cual decidimos no incluirlos en el corpus de textos con el que trabajamos aquí. Sin embargo, los mismos contienen aportes en torno de las categorías de "sugestión" y "contagio" que echan luz sobre las relaciones de conducción que se desarrollan en los contextos de masas. Para un tratamiento de estos últimos aspectos con relación a la temática de la conducción y el liderazgo, véase Blanco y Haidar (en prensa).

${ }^{14}$ Las muy breves referencias que efectuamos en los párrafos siguientes en torno de la tesis de la "fragmentación del yo" se encuentran inspiradas en la excelente reconstrucción que de dicha temática realiza Remo Bodei (2006) en su libro Destinos personales.

15 Tanto Taine como los especialistas franceses en psicopatología constituyen un marco de lecturas comunes a Le Bon, Tarde y Ramos Mejía. Si bien los análisis dedicados a Bunge han resaltado la incidencia que el psicólogo experimental alemán Wilhem Wundt tuvo sobre su obra, como destaca Terán (1998), el intelectual argentino había encontrado en de De l'intelligence de Taine un punto de apoyo, entre otros, para articular la matriz positivista desde la cual concibió su psicología social, con los puntos de vista idealistas que impregnan, asimismo, su pensamiento.

\footnotetext{
${ }^{16}$ Adentro de la aparente unidad de Rosas había dos: "un Rosas que mandaba, vigoroso, actuante y hasta agresivo; y otro Rosas que lo admiraba (...) El primero, agente pasivo, se dejaba admirar; el otro, activo, no parecía tener otra misión que la servil, del elogio y de la defensa violenta” (Ramos Mejía, 1904: 107).
}

toda una serie de debates de carácter político, jurídico y filosófico; muchos de los cuales reverberan en los planteamientos que los autores que aqui consideramos hicieron acerca de los líderes.

Así, el interrogante respecto de la responsabilidad penal en el caso de los delitos cometidos por la masa suscitó el interés respecto del accionar irreverente de ciertos "agitadores" (caudillos o meneurs) que lograban movilizar a un gran número de individuos (Bialakowsky y Blanco, 2019). Con una activa participación en tales discusiones, en sus escritos criminológicos Tarde (2015a y 2015b) avanzó en la caracterización de los factores que explicaban (si bien nunca del todo) la "sugestión" que los conductores (cabecillas, agitadores, etc.) ejercían sobre las muchedumbres ${ }^{13}$. De manera más amplia, la discusión por la autoría en materia penal también resultaba irrigada, hacia fines del siglo XIX, por las teorias psicopatológicas acerca de la "fragmentación del yo ${ }^{14 ",}$ las que, como veremos, resuenan en la caracterización psicosocial que los autores que aqui tratamos hicieron de los líderes. El primero en reconocer "científicamente" la inconsistencia del "yo" fue Hyppolite Taine, quien en De l'intelligence (1870) argumentó que la conciencia se descomponía en una miriada de sensaciones, imágenes e ideas. Posteriormente, las elaboraciones de los especialistas franceses en psicopatología, Théodule Ribot, Pierre Janet y Alfred Binet ${ }^{15}$, abonaron la idea de que el "yo" era un "agregado" de elementos (sensaciones, pequeños estados nerviosos, representaciones, etc.) que cooperaban entre sí. En tales aproximaciones, la conciencia es el resultado de la hegemonía, precaria e inestable, conseguida por uno de los múltiples focos de sensaciones, imágenes, etc., que componen el sujeto; razón por lo cual este nunca resulta inmunizado frente al riesgo de la desintegración. Victima de un proceso mórbido semejante, Juan Manuel de Rosas habria dado acabadas muestras, en la opinión de Ramos Mejía, de sufrir el síndrome de desdoblamiento de la personalidad descripto por $\mathrm{A}$. Binet ${ }^{16}$.

Más allá del terreno psicopatológico, todos los autores que aquí consideramos asumían que, sea bajo los efectos del "contagio" entre pares o de la "sugestión" ejercida por un jefe, en las situaciones de masa los individuos pensaban, sentían y actuaban de manera radicalmente distinta de como lo haría cada uno por separado. Alarmados por la orientación radical que a partir de la Comuna asumieron en Francia los levantamientos obreros, tanto Tarde como Le Bon observaron críticamente el rol que en tales situaciones desempeñaban los "agitadores socialistas". 
De Prácticas y discursos

Universidad Nacional del Nordeste

Centro de Estudios Sociales

Año 9, Número 14, 2020, Octubre

ISSN 2250-6942
¿ Inventores, apóstoles, ídolos o caciques? Una aproximación a la problematización del "Iíder" en los albores del pensamiento sociológico y psicosocial

Inventors, apostles, idols or chieftains? An approach to the problematization of the "leader" at the dawn of sociological and psycho-social thought

\begin{abstract}
${ }^{17}$ En el marco del proyecto de la Generación del 80, los gobiernos de Julio A. Roca (1880-1886; 18981904) impulsaron un conjunto de transformaciones que apuntaron a consolidar el Estado moderno e incorporar el país al mercado mundial como exportador de granos y carnes (Botana, 1994). Entre las medidas que se consideraron conducentes a la modernización del país estuvo la inmigración masiva.
\end{abstract}

${ }^{18}$ Hasta 1912, cuando se consagró el voto universal (masculino), secreto y obligatorio, ganar una elección dependía, en la práctica, de los procedimientos controlados por caudillos electorales, que incluían desde la compra lisa y llana de votos hasta la realización de los pasos conducentes al fraude electoral (Zimmermann, 1995).
No menos crítico fue el parecer que, del otro lado del Atlántico, los dirigentes socialistas y anarquistas suscitaron entre los miembros de las elites. Atento a las transformaciones que la masiva afluencia de inmigrantes estaba produciendo en su pais ${ }^{17}$, tanto como a los avatares de las masas en Europa, al final de Las multitudes argentinas, Ramos Mejía (1899: 185) se refiere, de manera condenatoria, al meneur proveniente de la "canalla virulenta que lo contamina todo", a quien consideraba un sustituto espurio de los individuos que en el devenir del proceso histórico argentino habian sido colocados a la cabeza de las multitudes de la emancipación.

Al igual que en Francia, en Argentina las masas urbanas fueron percibidas, desde diferentes aristas, como un factor de perturbación e inestabilidad. Pero, a diferencia de lo que sucedía en el país del Norte, además del interés por encontrar mecanismos que permitieran obturar las fisuras del orden social, en el horizonte de preocupaciones teóricas y prácticas que las mismas suscitaban entre los intelectuales argentinos latía una pregunta más urgente: cómo integrar a una población conformada por trabajadores e inmigrantes en el proceso, aun abierto, de constitución de la nación. En esa dirección, un problema que atraía por igual a Ramos Mejía y a Bunge, estaba dado por la integración de las multitudes a la vida política. Como consecuencia de las políticas implementadas durante las administraciones del presidente Julio A. Roca, el territorio argentino se fue tornando más urbano y cosmopolita, a la vez que más conflictivo. Si bien la estructura social experimentó un acelerado proceso de movilidad ascendente, la integración de importantes sectores de las masas trabajadoras e inmigrantes al mercado no se dio de manera acompasada con la participación en el sistema político. Hacia fines del siglo XIX, no solo una parte importante de la sociedad estaba excluida de las urnas, sino que, además, la política no suscitaba prácticamente interés entre una población que, fuese nativa o inmigrante, estaba principalmente abocada al enriquecimiento económico.

No menos alentador era el aspecto que tenía la escena política argentina cuando se la contemplaba desde el punto de vista de la actuación de las elites, la cual oscilaba entre la corrupción ${ }^{18}$ y la apatía. Críticos de la propia fracción social a la que pertenecian, mientras en sus escritos literarios Bunge no dejó de impugnar la corrupción del roquismo y el deseo desenfrenado de enriquecimiento que domeñaba a los porteños (Terán, 1998: 99), Ramos Mejía (1899:184) se lamentaba, al referirse a las multitudes modernas, del "achatamien- 
De Prácticas y discursos

Universidad Nacional del Nordeste

Centro de Estudios Sociales

Año 9, Número 14, 2020, Octubre

ISSN 2250-6942

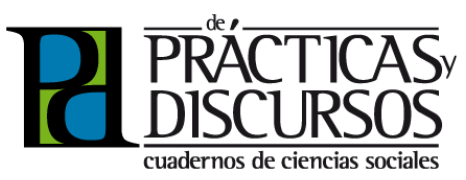

\begin{abstract}
${ }^{19}$ Así, en su Filosofía penal (1972:18), Tarde destacaba la incidencia de la crisis moral que, apenas notada por algunos pensadores, consideraba de más importancia y de más incalculables consecuencias que muchas "revoluciones sociales famosas".

\footnotetext{
${ }^{20}$ Tal expresión designa el mito que afirma que el curso y el progreso de la historia dependen de la voluntad de ciertos hombres extraordinarios (entre los que se cuentan profetas, reyes, guerreros, artistas y filósofos) que despiertan en los pueblos sentimientos de admiración y vínculos de sumisión, dando lugar a un verdadero culto (Haidar, 2020).
}

to político e intelectual" que afectaba a la sociedad de su tiempo. Tales eran, en la opinión de los autores argentinos, algunos de los sintomas de una crisis que, al igual que sus pares del Norte, reconducian al terreno de la moral ${ }^{19}$.

En un clima intelectual dominado por el quiebre de la confianza en torno de la unidad del "yo" y la destitución de la importancia otrora conferida a los "grandes hombres ${ }^{20 "}$, un rasgo de las conexiones en simultáneo que pueden trazarse entre los discursos de los cuatro autores considerados está dado por la percepción de la (cada vez más) escasa incidencia que los individuos tenian en la historia. Motivado por las circunstancias político-sociales de su coyuntura, Le Bon era de la idea de que las enseñanzas de la psicología no podían servir para gobernar a las masas, sino, apenas, para no dejarse gobernar demasiado por ellas. Un pesimismo semejante invadía a Carlos Augusto Bunge, quien se lamentaba porque el peso del "gran número" que la democracia, afirmaba, aplastaba al individuo excepcional (Terán, 1998).

Lejos de la inquietud angustiante que trasuntan los escritos de Le Bon, o del desánimo con el que el autor de Nuestra América constataba el ocaso de los espíritus independientes, los textos de Tarde y de Ramos Mejía convergen en afirmar, de un modo que no está privado de entusiasmo, el poder de lo "infinitamente pequeño". Así, tras criticar el "antropomorfismo histórico-político" que había guiado la interpretación de la emancipación argentina en la prosa de autores consagrados, Ramos Mejía (1899: 24) concentró su atención sobre la figura, democrática por excelencia, de la multitud, en la que veía el recurso y la fuerza de los pequeños y anónimos.

Por su parte, en varios pasajes de Las leyes de la imitación, entre otras obras, Gabriel Tarde señaló el error de concentrarse en los "grandes hombres" como protagonistas de la historia, siendo que, como veremos en el apartado siguiente, las invenciones de las cuales nacian las corrientes imitativas a partir de las cuales se configura lo social dependian del accionar anónimo e infinitesimal de una multitud de hombres comunes.

\section{LA JEFATURA DE LOS "INVENTORES" Y LOS "APÓSTOLES DE LO NUEVO"}

Entre las diferentes formulaciones producidas a horcajadas de la sociología y la psicología social que, hacia fines del siglo XIX, pu- 
De Prácticas y discursos

Universidad Nacional del Nordeste

Centro de Estudios Sociales

Año 9, Número 14, 2020, Octubre

ISSN 2250-6942
¿ Inventores, apóstoles, ídolos o caciques? Una aproximación a la problematización del "Iíder" en los albores del pensamiento sociológico y psicosocial

Inventors, apostles, idols or chieftains? An approach to the problematization of the "leader" at the dawn of sociological and psycho-social thought

sieron en discurso la cuestión de los líderes, aquellas que provienen de Las leyes de la imitación se distinguen porque constituyen "piezas" de una teoría que hace de "lo político" un elemento constitutivo de toda relación social. Declinando la teoría social de la teoría política, Tarde entiende que la constitución de todo cuerpo (y en lo que a nosotros nos interesa, del cuerpo social) se remonta a relaciones de mando y de obediencia (Lazzarato, 1999).

Lo social consiste, para el autor, en una trama de relaciones de imitación formada a partir de una acción originalmente individual, que en virtud de la facultad mimética que caracteriza a todo lo existente, se reproduce y generaliza. Entre las distintas formas que pueden asumir tales vínculos, el mismo reconoce la primacía (lógica e histórica) de la imitación "unilateral", basada en el mando o en la sugestión, por sobre la imitación "reciproca".

Evocada, en Las leyes de la imitación, con los vocablos "jefe" (chef) y "maestro" (maître), y solo una vez con el término leader (empleado directamente en inglés), la noción de líder no reviste, en la obra de Tarde, el carácter de una categoría de pensamiento autónoma. Pero participa, en cambio, de la díada "conductor-conducido" que en su edificio teórico asume el estatuto de una relación social fundamental. Como señala en Las leyes sociales (2013), la relación entre dos personas, una de las cuales actúa espiritualmente sobre la otra, es el "elemento único y necesario" de la vida social.

En todos los periodos históricos (tanto en las sociedades primitivas como en las modernas) y en cualquier ámbito de interacción (ya sea la familia, la escuela, el taller, el partido, etc.) es posible identificar el funcionamiento de ciertos elementos "jefes" (el amo sobre el súbdito, el maestro sobre el discípulo, el profesor sobre el alumno, el padre sobre el hijo, el líder sobre la masa, el periodista sobre el público, etc.) que operan como focos de irradiación de ejemplos. Ávidos de expandirse, los mismos logran instituirse como puntos de vista privilegiados, permitiendo la reunión en la heterogeneidad.

La pregunta por las razones que explican por qué a lo largo de la historia ciertos hombres revisten, para otros, el papel de modelos, da lugar a una serie de desarrollos que constituye el material con el que se arma, en la sociología psicológica tardeana, un perfil singular de jefe.

Lejos de reclutarse entre los "prójimos" o de pretender, recurriendo a algún artificio, asemejarse a los conducidos (como, según nos informan los autores argentinos, hacian los caudillos hispa- 
De Prácticas y discursos

Universidad Nacional del Nordeste

Centro de Estudios Sociales

Año 9, Número 14, 2020, Octubre

ISSN 2250-6942

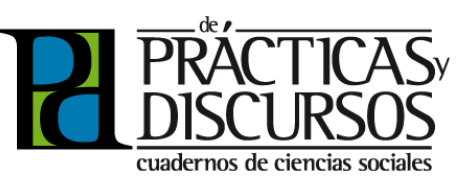

${ }^{21}$ Según la concepción relacional de todo lo existente que sostiene Tarde, no solo la superioridad social, sino todo fenómeno que en virtud del sentido común tendemos a captar como unidad o sustancia, no es, en realidad, más que una serie de pequeñas repeticiones jerarquizadas alrededor de una fuerza polarizante (Lazzarato, 2018). noamericanos, maestros en el arte de simular), jefe es quien se considera socialmente "superior ${ }^{21 " . ~ M e z c l a n d o ~ t e ́ r m i n o s ~ e ~ i m a ́-~}$ genes médico-biológicas con otros procedentes de la novel ciencia que por entonces constituía la sociología, Tarde se refiere al mismo como un "foco" de irradiación de las corrientes imitativas, cuya superioridad se trata de emular porque se la cree o juzga propia para lograr los bienes que, en cada momento histórico, los individuos y grupos consideran valiosos.

En tal esquema, la superioridad (o, en otras palabras, el "prestigio") adquiere un valor "funcional" (Borch, 2019), es el medio o el "canal" por donde pasan (se expresan, encuentran una salida) los flujos de deseos, necesidades, expectativas, en principio indeterminados y vagos, de los individuos del grupo sobre los que la misma incide. Como se expresa sintéticamente en Las leyes de la sociedad, líder es quien responde, en palabras o en hechos, a la pregunta, verbal o tácita, que otros han formulado (Tarde, 2013). Según esta forma de razonar, la "orden" (al igual que, en otros escenarios, menos jerarquizados, el "consejo") cuenta menos por lo que involucra en términos de coerción que por su rendimiento social: es aquello que da salida a un cúmulo de aspiraciones impotentes e indeterminadas, de "necesidades de fe sin idea o de actividad sin medio de acción" (Tarde, 2011: 201).

Si bien los aspectos a partir de los cuales las sociedades reconocen la superioridad de un hombre son históricamente variables, tras una ojeada retrospectiva al "pasado remoto" de las civilizaciones, el autor llega a la conclusión de que aquello que mancomuna a los personajes semifabulosos a quienes las leyendas atribuyen la revelación de oficios, conocimientos, leyes, etc., es el hecho de que todos ellos se comportaron, históricamente, como "inventores" o "importadores de invenciones", en una palabra, como "iniciadores" (Tarde, 2011: 209-210).

En consonancia con lo anterior, dos perfiles reúnen las condiciones para encarnar roles de liderazgo. Por un lado, el genuino "inventor": esto es, aquel que al introducir una diferencia inaugura un "linaje imitativo" (Tarde, 2013) que viene a sumarse a todos los existentes y de cuyo entrecruzamiento surge lo social. Pero, además de esa significación grandiosa, emparentada con la idea de genio, en la sociología tardeana la invención asume, asimismo, la significación más modesta y prosaica de "iniciación". De allí que el papel de líder también esté reservado al individuo que posee cualidades que lo habilitan para comprender y explotar, mejor que 
De Prácticas y discursos

Universidad Nacional del Nordeste

Centro de Estudios Sociales

Año 9, Número 14, 2020, Octubre

ISSN 2250-6942
¿ Inventores, apóstoles, ídolos o caciques? Una aproximación a la problematización del "Iíder" en los albores del pensamiento sociológico y psicosocial

Inventors, apostles, idols or chieftains? An approach to the problematization of the "leader" at the dawn of sociological and psycho-social thought

el resto, el cúmulo de invenciones ya realizadas (Tarde, 2011).

En tanto "inventor", el conductor es un homo faber, un ser que venciendo la pereza (análoga a la inercia material) a la que, dominada por la reproducción, lo inclina a la vida social, se toma el trabajo de crear. En ese sentido, el sociólogo francés se revela como un teórico del líder transformador que, a través de la práctica de la invención, pone en suspenso lo que hay de habitual en lo social; actuando, metafóricamente, como un ser despierto y consciente entre una multitud de sonámbulos.

Según un modo de pensar que reencontraremos en la célebre caracterización que Joseph Schumpeter hiciera del "empresario", la innovación requiere una audacia extraordinaria; puesto que para "despertarse un momento del sueño familiar o nacional, el individuo debe salirse momentáneamente de su sociedad" (Tarde, 2011: 215-216).

No solo por la fuerza que debe movilizar para vencer la pereza de imitar, sino por la temporalidad accidental e intermitente con la que ciertas corrientes y rayos de imitación preexistentes se entrecruzan en un cerebro más o menos excepcional (Tarde, 2011), el inventor introduce una ruptura en la historia.

Pero aun cuando escapa a la lógica reproductiva de lo social, siendo posible atribuirla a "un" (algún) individuo, la invención no es un acto enteramente creativo ni necesariamente extraordinario o grandioso. Por el contrario, es el resultado de la cooperación de una multitud de agentes sociales e infinitesimales, de la selección y combinación (realizadas, ciertamente, por un cerebro "más o menos excepcional") de una multiplicidad preexistente de modestas e ignotas innovaciones (Lazzarato, 2018: 365).

En esta forma de razonamiento los "grandes hombres" pierden brillo, siendo reducidos al papel más prosaico de "iniciadores" $y$, sin sacrificarse por completo, la genialidad encuentra su cifra en la selección y combinación de ideas ordinarias provenientes de "pequeños hombres desconocidos" (Tarde, 2011: 210).

A través de toda una serie de desplazamientos (desde lo "único" hacia lo "múltiple", lo "grandioso" a "lo pequeño" y lo "célebre" a lo "infame"), el autor contribuye a pensar la innovación y, por lo tanto, el liderazgo y la autoridad, de un modo más democrático. Tal efecto, derivado del trabajo de la teoría, resulta reforzado por el diagnóstico que el mismo produce de la modernidad, en la que observa tanto una democratización en la facultad de imitar como una aceleración en el ritmo de la imitación. Este último 
De Prácticas y discursos

Universidad Nacional del Nordeste

Centro de Estudios Sociales

Año 9, Número 14, 2020, Octubre

ISSN 2250-6942

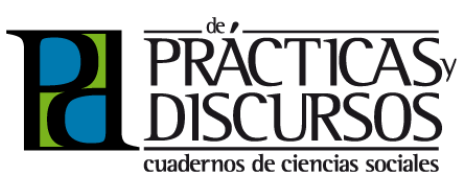

\begin{abstract}
${ }^{22}$ Aunque valora la actuación de los "creativos" que perturban las curvas estadísticas, su concepción de la imitación está lejos de ser meramente reproductiva o pasiva. Por el contrario, Tarde (2011: 258) sostiene que la modernidad "estimula la ingeniosidad de la imitación” y que la mayor propensión a la uniformidad que se produce de la mano de la democratización de la imitación genera las condiciones para que se desarrolle cierto refinamiento en la copia, consistente en producir "otra versión" de lo mismo.
\end{abstract}

aspecto lo lleva a constatar, no sin cierta nostalgia, que la "verdadera invención" resulta cada día más dificil, así como a conjeturar que sería cada día más rara (Tarde, 2011: 258).

Si el papel conductor del "genuino inventor", cada día más bizarro, consiste en introducir novedades que evitan el entumecimiento social, del discurso psicosociológico que estamos considerando emerge otro perfil de "jefe" cuya función consiste en coadyuvar a la irradiación social de las innovaciones, generando la confianza necesaria para que los juicios y deseos individuales se transformen en juicio y deseos colectivos.

Avocados a generar la "opinión" sin la cual una invención carece de existencia social, "héroes", "primeros capitanes", "hombres de Estado", no menos que "periodistas políticos", fungen como "servidores inconscientes" de innumerables y obscuros inventores (Tarde, 2011: 216).

Teniendo en cuenta que contribuyen a generar una "fe común" a través de una labor de "propaganda", resulta comprensible que, para poner en discurso a este otro grupo de conductores, el autor haya tomado en préstamo figuras provenientes del pastorado cristiano.

Según esta lógica, el jefe es un "misionero" o "apóstol" de una idea, hacia la cual atrae y agrupa a otros hombres, contagiándoles la fascinación que el mismo siente por ella.

Es que, a diferencia del genuino inventor que escapa, si bien momentánea y accidentalmente, a los efectos magnetizadores de la sugestión, el tipo de fascinación que el "apóstol" genera le ha sido previamente contagiada por una idea que lo mantiene cautivado. Impulsado, destaca el autor, siempre por un deseo potente (de conquista, regeneración, de inmortalidad, etc.), la performance directiva de estos líderes resulta precedida por el "encuentro" con una "idea" que les permite canalizar las propias aspiraciones y con la que se vinculan de un modo religioso, cuasi místico. Se trate de la creencia en la resurrección, o del principio de la soberanía del pueblo, tal idea "le obliga" y "le exalta" y "helo convertido en apóstol" (Tarde, 2011: 163).

Seducido por el prestigio de aquello en lo que cree fervientemente, para hacer que su fe se divulgue, el apóstol apela a incentivar la "curiosidad" de las muchedumbres, las que, predispuestas a "dejarse ganar" por cualquier idea o deseo que se insista en popularizar, resultan "presa fácil" (Tarde, 2011: 310) para tal clase de líderes. Como veremos en el apartado siguiente, al igual que los "apóstoles de lo nuevo", tanto los "agitadores socialistas" como los "cruzados 
De Prácticas y discursos

Universidad Nacional del Nordeste

Centro de Estudios Sociales

Año 9, Número 14, 2020, Octubre

ISSN 2250-6942
¿ Inventores, apóstoles, ídolos o caciques? Una aproximación a la problematización del "Iíder" en los albores del pensamiento sociológico y psicosocial

Inventors, apostles, idols or chieftains? An approach to the problematization of the "leader" at the dawn of sociological and psycho-social thought

del orden" a los que Le Bon se refirió en Psicología de las masas cimentan su autoridad en un mito rector. Solo que, para ganarse el alma de la multitud, volviéndola adicta a aquello mismo que, en algunos casos, los embriaga por completo, lo que hacen, en lugar de estimular el deseo de saber, es infundir esperanza.

\section{LOS LÍDERES COMO "APÓSTOLES DEL ORDEN"}

Gran parte de las reflexiones que Gustave Le Bon dedicó a la temática de los líderes se desgaja del cuadro de época que él mismo retrata en su afamada Psicología de las masas, un pequeño libro escrito con un tono apodíctico (Van Ginneken, 1992), que recoge y divulga, en un lenguaje popular, varias de las ideas científicas acerca de los comportamientos de las multitudes, producidas desde el campo de la historia, la criminología y la sociología, y que incluían los aportes que el propio G. Tarde había hecho a tal problemática.

Surgido al calor de una agenda política específica, caracterizada por el temor que generaba entre los conservadores el poder que habian adquirido las masas "rojas", el libro parte de la asunción de la muy modesta posibilidad de acción que, frente a ese movimiento, poseian los meneurs. Además de este último vocablo, que remite a la idea de "conductor" o "guía", en Psicología de las masas la noción de líder aparece connotada con los términos maître (amo) y chef (jefe).

Si bien la composición que Le Bon se hacía de la sociedad en la que vivía era pesimista, pensaba (à la Marx) que, adecuadamente encuadrados, los aspectos problemáticos de la realidad ofrecian herramientas para su solución. Así, aun cuando repudiaba la actuación de los dirigentes sindicales que movilizaban en torno de sí a cientos de hombres, no dejó de prestarle atención, en el entendimiento de que la misma ofrecía lecciones útiles para la formación de los amos de las multitudes latinas a quienes sus trabajos estaban principalmente dirigidos, incluyendo a aquellos de las "tristes repúblicas latinas de América" (Le Bon, 1912).

Es que, en la opinión del autor, a diferencia de los pueblos anglosajones, que eran capaces de autogobernarse, los pueblos latinos experimentaban, en virtud de su propia composición racial, la necesidad, irresistible y perpetua, de ser protegidos por un amo (Le Bon, 1912). Desgajada de un tal esquema determinista-biológico y racista de pensamiento, la noción de conductor es tran- 
De Prácticas y discursos

Universidad Nacional del Nordeste

Centro de Estudios Sociales

Año 9, Número 14, 2020, Octubre

ISSN 2250-6942

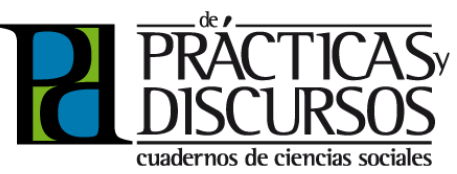

shistórica. Así concebida, carece, en la obra del médico francés, de vuelo teórico propio, siendo más bien una arista de la noción de "multitud" o, incluso, de "pueblo", en torno a las cuales giran sus escritos de psicología social.

Partiendo de ese presupuesto, tomó nota de que las masas obreras irrumpian en la escena política de su tiempo de la mano de líderes que tenían la misma extracción social, y a los cuales llama, peyorativamente, "agitadores", "apóstoles del desorden" o "apóstoles revolucionarios". La elección del término "apóstol", que comparte con Tarde, dice de la función que confería a los líderes: insuflar y propagar una "fe" (religiosa o secular) entre los integrantes de las multitudes, gobernándolas mediante la manipulación de las fuerzas irracionales que constituian las creencias y los sentimientos. Según el modo de pensar del autor, lejos de situarse en una posición de exterioridad respecto de la gran idea o mito que propaga, el líder resulta, la mayoría de las veces, mené y envahi, "guiado" e "invadido" por ella, convirtiéndose en su apóstol (Bodei, 2006: 357). De acuerdo con este modo de pensar, la fascinación que tal clase de apóstoles ejerce sobre las multitudes es una irradiación de la que ellos mismos experimentan antes. "Hipnotizados por sus ensueños acaban por alucinar a las multitudes y las lanzan furiosamente contra todos los obstáculos" (Le Bon, 1912: 411).

Explotando la asociación entre "genio" y "locura" planteada hacia mediados del siglo XIX por Moreau de Tours, en Psicología de las masas, Le Bon (1986: 90) postula la afinidad que los "excitados y semi-alienados" que se encontraban al borde de la locura demostraban para desempeñarse como conductores de las multitudes. Era a esa clase de espíritus alucinados, que repetían, sintomáticamente, las mismas cosas en los mismos términos, a los que la elite debía, no obstante, emular, si es que quería "conducir" o, al menos, no dejarse gobernar (demasiado) por las masas. Así, si bien el diagnóstico de la coyuntura que Le Bon delineara asumía que era "demasiado tarde" para apelar a la moralidad del burgués conquistador, del individuo heroico, también reconocía que, si se actuaba de manera inmediata, aún habia tiempo de frenar el proceso de decadencia y desorganización en el que la civilización se encontraba inmersa (Geroulanos, 2014: 20).

Es así que, además, de conferirle un valor ontológico (como se lee en el texto que publicó en 1895, "las masas son rebaños que no sabrian carecer de líderes") y de utilizarla para describir la 
De Prácticas y discursos

Universidad Nacional del Nordeste

Centro de Estudios Sociales

Año 9, Número 14, 2020, Octubre

ISSN 2250-6942
¿ Inventores, apóstoles, ídolos o caciques? Una aproximación a la problematización del "Iíder" en los albores del pensamiento sociológico y psicosocial

Inventors, apostles, idols or chieftains? An approach to the problematization of the "leader" at the dawn of sociological and psycho-social thought

\begin{abstract}
23 “'Los lazos sociales creados por la civilización sólo se mantienen mediante un esfuerzo constante. Una de las causas de la decadencia es renunciar a este freno creyéndole inútil” (Le Bon, 1912: 414).
\end{abstract}

${ }^{24}$ Mediante su argumentación, Le Bon legitima el "autoritarismo al interior del liberalismo" (Haidar, 2019), en la forma transitoria y excepcional de la dictadura. "El hombre que sabe gobernarse por sí mismo no pide ser gobernado por los otros, ya que posee una disciplina interior que lo exime de toda disciplina exterior. Es el dictador de sí mismo y nada reemplaza semejante dictadura" (Le Bon, 1924: 232; traducción de la autora). actuación de un tipo histórico de dirigente (los cabecillas de las multitudes socialistas), el autor atribuyó a la categoría de líder el valor, político-práctico, de un artefacto de conducción. Sensible a las enseñanzas que se desprendian de la psicología de las masas, el "apóstol del orden" leboniano emerge como respuesta frente a las "faltas" o déficits de la voluntad que aquejaban tanto a la base como a la cumbre de la pirámide social.

En cuanto al primero de ambos aspectos, uno de los ejes en torno al cual giran los planteos psicopolíticos del autor es que los fenómenos de masas entrañaban una "vuelta atrás" del proceso evolutivo del organismo social hacia el irracionalismo. En lo que al problema del autogobierno concierne, tal retrogradación se traducia en el hecho de que los pueblos latinos (a diferencia de los anglosajones) habian dejado de poner atención y esfuerzos en controlar sus impulsos atávicos ${ }^{23}$; con las consecuencias que ello había traído aparejado en términos de desorganización.

Asimismo, el autor se lamentaba de la impotencia de las elites, las cuales sufrian de irresolución, falta de visión de conjunto y de confianza en la propia visión. En ese contexto de voluntades lábiles, apelaba a la intervención, autoritaria, de hombres de voluntad "fuerte" y "tenaz" que, en la medida en que sabian controlar sus propios instintos ${ }^{24}$, podian conducir a otros.

A diferencia del "cacique" que, como veremos en el cuarto punto del trabajo, administra la paz social mediante una maquinaria prebendaria cuidadosamente aceitada, y de los conductoresmodelos que, à la Tarde, conseguian imponer ciertas ideas tanto a través de la lucha como de la cooperación (y las más de las veces en virtud de esta última), el líder leboniano está inexorablemente inmerso en una dialéctica bélica.

Concebido, en sí mismo, como "reacción" frente al avance de las multitudes socialistas comandadas por cabecillas de verba inflamada, es el apóstol del orden frente a los apóstoles revolucionarios, cuya maniobras de propagada copia, no obstante, en una actitud francamente defensiva y, con ello, manifiestamente bélica. Artefacto de la "defensa social", está Ilamado a iniciar, a partir de la actitud mimética que Le Bon le recomienda adoptar, una guerra que, desde el punto de vista del autor, solo puede finalizar una vez que se haya conseguido aplacar la amenaza revolucionaria.

Siendo que "los apóstoles solo se combaten con otros apóstoles" (Le Bon, 1912: 412), la función de los "apóstoles del orden" consiste en contrarrestar la avanzada de la fe socialista, creando, 
De Prácticas y discursos

Universidad Nacional del Nordeste

Centro de Estudios Sociales

Año 9, Número 14, 2020, Octubre

ISSN 2250-6942

\footnotetext{
${ }^{25}$ Como señala Terán (2010), hacia fines del siglo XIX el término líder no formaba parte del diccionario político de los argentinos.
}

o mejor "recreando", "reviviendo" una antigua fe, mediante la movilización de las imágenes, palabras y creencias que yacian inactivas en el fondo de reserva espiritual que constituía, en la concepción del autor, el alma de las multitudes.

Para conducirlas, el jefe se nutre de las energías de reserva que constituye el inconsciente, donde se acumulan las convicciones más profundas, transmitidas por la ininterrumpida cadena del atavismo (Bodei, 2006). Lejos de orientarse hacia el futuro, a los efectos de cumplir tal cometido, el líder debe convertirse en el intérprete privilegiado de la "imperiosa voluntad de los muertos" (Le Bon, 1927: 38), "nuestros amos verdaderos" (Le Bon, 1912: 424). La eficacia sugestiva de los líderes, tanto socialistas como conservadores, resulta irrigada por la esperanza que el propio mito contagia. Pero a diferencia de los primeros, el dirigente de "voluntad férrea" no solo no surge de las masas, sino que, además, se ubica en una posición de exterioridad respecto de las viejas ideas y creencias que se propone reflotar.

Inficionado con el veneno del escepticismo, en ausencia de toda actitud "natural" con respecto al mito, se sirve calculadoramente de él. Guiado por las recomendaciones que surgen de la ciencia, en sus manos lo "irracional" es tan solo un instrumento de lo racional. De allí que, dada su ajenidad respecto de las masas, recurra al engaño como medio de gobierno, permutando las palabras "viejas" por otras "nuevas", pero sin tocar para nada las propias cosas (Le Bon, 1986: 82).

Como veremos en el apartado siguiente, Ramos Mejía se sirvió de una versión particularmente sofisticada de engaño, la "simulación de talento", para diseccionar el rol que los líderes caudillistas cumplieron a lo largo de la historia argentina.

\section{LOS "ÍDOLOS" A LA CABEZA}

Al igual que sucede con los escritos de Gabriel Tarde y Gustave Le Bon, en los trabajos de José María Ramos Mejía la noción de "jefe" solo funciona en tándem con otras nociones o conceptos que los vertebran. En efecto, lejos de dar nombre a un concepto, en Las multitudes argentinas tal término, no menos que el vocablo meneur, al que el autor recurre directamente del francés ${ }^{25}$, se utiliza para connotar uno de los elementos que componen la categoría de multitud, en torno a la cual se desarrolla todo el libro.

Si bien en la lectura ramosmejiana la misma posee una doble valen- 
De Prácticas y discursos

Universidad Nacional del Nordeste

Centro de Estudios Sociales

Año 9, Número 14, 2020, Octubre

ISSN 2250-6942
¿ Inventores, apóstoles, ídolos o caciques? Una aproximación a la problematización del "Iíder" en los albores del pensamiento sociológico y psicosocial

Inventors, apostles, idols or chieftains? An approach to the problematization of the "leader" at the dawn of sociological and psycho-social thought

\begin{abstract}
${ }^{26}$ En la reconstrucción de la historia argentina que efectúa Ramos Mejía, la imaginación aparece como una facultad ambivalente: por un lado, es una facultad productiva, activa; el dinamismo social, depende, en gran medida del poder creativo de las multitudes que poseen dicha facultad en forma superlativa. $Y$, al mismo tiempo, es pueril y susceptible de ser vivamente impresionada, "artera" (1899: 149), fuente de error y de las deformaciones de la realidad.
\end{abstract}

\footnotetext{
${ }^{27}$ El resaltado pertenece al autor.
}

cia "teórico-abstracta" e "histórico-concreta", como argumentamos a lo largo de este apartado, los desarrollos relativos a los conductores se desprenden del funcionamiento de la multitud como unidad para el análisis sociohistórico de la política argentina.

En Los simuladores del talento, en cambio, los mismos forman parte de la problemática ético-política que, en la visión del autor, encierra la figura del "caudillo"; la cual, enfocada desde la perspectiva de la "simulación", adquiere hondura psicológica. En esa dirección, el propio autor presenta su libro como el estudio de las "facultades defensivas" que los caudillos aplicaron a la gestión política, consideradas en la sociedad general, y en la sociedad argentina en particular (1904: xiii).

Entendido como dimensión de la multitud en su vertiente histórico-concreta, conductor "es colocado" y "se coloca" en el lugar de lo que no está; es decir, en el plano de las imágenes, de las apariencias. Es la imagen que permite a "los muchos" que conforman la multitud reconocerse como unidad.

Esa coproducción, a la vez colectiva y singular, se deduce de la consideración simultánea de Las multitudes argentinas, texto en el que su emergencia se explica desde el punto de vista de los movimientos de masas, y de Los simuladores del talento, donde el foco está puesto en los individuos que lideran.

Ambas aproximaciones se complementan. La simulación, formación sintomática mediante la cual el líder encubre su falta de talento, se empalma con las proyecciones fantasiosas de las masas que, para suplir su propio déficit, transforman un rasgo personal cualquiera en objeto de identificación. Así, en el libro de 1904 el eje está puesto en una formación sintomática individual, en un mecanismo de defensa: la simulación del talento. Al desplegarse, tal mecanismo hace sistema, se anuda con el "colosal poder de ilusión y fecundidad deformativa" (1899: 25) que caracteriza a las multitudes ${ }^{26}$.

La atmósfera de efervescencia en la que se despliega la sociabilidad rural con posterioridad a la emancipación ofrece las condiciones propicias para que las personalidades plásticas consigan capitalizar sus disposiciones simuladoras, transformándose en los ídolos que sintetizan y materializan los sentimientos y apetitos populares. De alli que cuando la agitación social toma grandes proporciones, el ser caudillo ${ }^{27}$ Ilega a constituir una profesión (Ramos Mejía, 1904: 57).

En la galería de conductores que jalonan el sinuoso itinerario que las multitudes recorren hasta el acontecimiento de la emancipa- 
De Prácticas y discursos

Universidad Nacional del Nordeste

Centro de Estudios Sociales

Año 9, Número 14, 2020, Octubre

ISSN 2250-6942

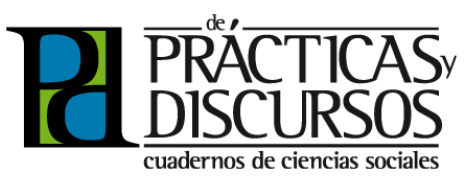

\begin{abstract}
${ }^{28}$ Como señala Alejandra Mailhe (2016: 56), en Las multitudes argentinas "opera cierta teleología, según la cual las fuerzas desatadas por las primeras rebeliones religiosas en la colonia se transmutan en los movimientos de masas que intervienen en las guerras de emancipación, en un proceso de evolución hacia la política, no exento sin embargo de grandes -y crecientes- peligros".
\end{abstract}

\footnotetext{
${ }^{29}$ No sin un dejo de melancolía, el alienista argentino anhelaba para su sociedad la restitución de la tradición que el aluvión inmigratorio había interrumpido, amenazando, según su visión aristocrática, con arrebatarle la "fisonomía nacional" (Ramos Mejía, 1899: 176). Para contrarrestar tal tendencia confiaba, no obstante, en el poder fijador y estabilizador que a los efectos de la formación del carácter nacional podía tener la educación. En esa dirección, la atención que dedicó, en el libro Rosas y su tiempo (1907), a las fiestas populares y liturgias a partir de las cuales, entre otros elementos, el caudillo Juan Manuel de Rosas construyó y mantuvo, a lo largo del tiempo, su liderazgo sobre las multitudes rurales y urbanas, puede vincularse, como sugieren Devoto y Pagano (2009), con su accionar como presidente del Consejo Nacional de Educación, cargo desde el que se ocupó de promover una pedagogía y una liturgia patriótica, en la esperanza de infundir, entre los inmigrantes, el sentimiento de la nacionalidad.
}

ción, un lugar destacado lo ocupan un conjunto de personajes que siendo expresión de formas de religiosidad y espiritualidad popular (frailes, nigromantes, etc.) inocula en el pueblo cierto "impulso confuso de rebelión mezclado a un fuerte espíritu de misticismo peculiar" (Ramos Mejía, 1899: 33).

En tal trayectoria, el espíritu de rebeldia decanta para el lado de la política ${ }^{28}$. Pero en una línea (biologicista y racista de argumentación) que Nuestra América de Bunge lleva al paroxismo, el autor no deja de percibir en los caudillos (que al igual que los nigromantes del pasado se daban aires de iniciados) el trabajo del "fetiquismo político" de un pueblo por cuyas venas circula sangre de indio y de mestizo (1904: 193).

"Fetichismo", sí, porque supliendo la ausencia de "facultades de relación" que caracteriza a las clases populares, el meneur funge como molde o receptáculo (un medio, en fin) adónde afluyen (y se fusionan) los apetitos inferiores de cada uno (Ramos Mejía, 1904: 58). Es en virtud de esa maniobra proyectiva que los mismos se convierten en las "las antenas y los ojos" por donde los hombres que la componen tocan, miran y sienten las cosas de la vida (Ramos Mejía, 1899: 108).

De alli que tal lugar esté vedado a los hombres de carácter fuerte. Las "personalidades de acero, los hombres de bronce bismarkiano no se dejan deformar por el dedo de esa extraña escultora", que para hacer su obra requiere no el acero, sino la "cera dócil" de las medianías pedestres o poco conocidas (Ramos Mejía, 1904: 183). A diferencia de Le Bon, que encuentra en el "alma de la raza" la sustancia nutricia del poder sugestivo del líder, Ramos Mejía devela la banalidad de la identificación que, en su opinión, se genera a partir de "cosas deleznables e insignificantes" (1899: 135). Al tanto de los avatares de la historia política de su país, el autor era consciente de que la gobernabilidad de las masas había dependido, en Argentina, del encuentro, contingente (cuando no azaroso) y siempre efímero, con individuos que habian funcionado, efectivamente, como focos de atracción de los anhelos y pasiones populares en virtud de factores que, a diferencia de lo que Le Bon entreveía como posibilidad para Francia, estaban muy lejos de gozar de la estabilidad y continuidad de la que gozaba, en tal país, la tradición ${ }^{29}$.

Lejos del genio creativo o de las facultades para capilarizar socialmente una idea que Tarde atribuye a los líderes, el médico argentino llama la atención sobre el papel que desempeña la 
De Prácticas y discursos

Universidad Nacional del Nordeste

Centro de Estudios Sociales

Año 9, Número 14, 2020, Octubre

ISSN 2250-6942
¿ Inventores, apóstoles, ídolos o caciques? Una aproximación a la problematización del "líder" en los albores del pensamiento sociológico y psicosocial

Inventors, apostles, idols or chieftains? An approach to the problematization of the "leader" at the dawn of sociological and psycho-social thought

\begin{abstract}
${ }^{30}$ Junto a otros médicos-filósofos, hacia fines del siglo XIX Binet se ocupó de articular una sospecha con relación a la supuesta unidad y consistencia del yo. Con su libro On Double Personality, aparecido en Chicago en 1890, el autor dio impulso decisivo a los estudios estadounidenses sobre las personalidades múltiples (Bodei, 2006).
\end{abstract}

\footnotetext{
${ }^{31}$ Ramos Mejía confiere importancia a una serie de experiencias prosaicas de la biografía de Rosas que había sido significativa en su formación de líder de masas: su desempeño como mayordomo, capataz, peón de estancia, pinche barrendero de tienda; su experiencia como comandante de campaña y meneur del gauchaje alborotado, etc. (Haidar, 2020).
}

${ }^{32}$ El giro "política criolla" y la tesis que encierra (esto es, la existencia de un correlato lógico y epistemológico entre una psicología colectiva y la forma de la vida política) tuvo gran fortuna, tanto entre los contemporáneos de Bunge -así, Ramos Mejía utiliza esa expresión para caracterizar la política durante el régimen de Rosas (Haidar, 2020)-, como en el futuro. Si Bunge la utilizó en un sentido negativo, para designar el conjunto de "tejemanejes" que ciertos individuos despliegan para acceder a posiciones de poder y mantenerse en ellas, en la década de 1960, los ensayistas de la llamada "izquierda nacional”, la emplearán para designar el artilugio fundamental de las tradiciones culturales europeizantes y antipopulares (Del Brutto, 2000). sexualidad en la construcción social de la superioridad. "Se principia por tener un buen caballo (...) Luego, cuando se tiene un aspecto hermoso, o cuando menos físicamente prominente y llamativo, el buen caballo completa la impresión escultural que aquella produce y que encierra para ellos [sic] la verdadera idea de superioridad" (Ramos Mejía, 1899: 124-125).

Instigado por la incógnita que encerraba el fenómeno del caudillaje, en Los simuladores del talento el autor explora los factores psicológicos que hacian que ciertos hombres devinieran, sin saberlo, en "prosadores (...) de la política y la historia" (Ramos Mejía, 1904: 54). En un modo de razonamiento que declina de la fecunda idea que amaña locura con genialidad, Ramos Mejía (que ya había seguido esa pista analítica en una obra anterior) postula la afinidad que los hombres que padecian el síndrome de la personalidades múltiples descrito por Alfred Binet (1858-1911)30 demostraban para actuar como conductores de las multitudes.

Al tanto de las investigaciones de los psicólogos experimentales, el médico argentino se interesó por las posibilidades interpretativas que, en relación con las prácticas políticas que le preocupaban, abría la asunción de que el "yo" era un agregado de elementos.

En esa dirección, se refirió a los caudillos como excelsos transformistas, capaces de elaborar la personalidad requerida por las circunstancias y el clima social reinante, con los elementos que llevaban dentro.

Entre el conjunto de "simuladores" a los que en el libro de 1904 pasa revista, se destaca Juan Manuel de Rosas quien, por las vicisitudes de su biografia ${ }^{31}$ había sabido manejar con destreza aquello que Ramos Mejía (1904: 104) Ilamaba, metafóricamente, la "clavija misteriosa", esto es, la llave interna que, en palabras del autor, era capaz de hacer de la "santa" "prostituta" y del "monje" "marinero". Según desarrollaremos en el punto siguiente, al igual que el médico, que extrajo del pasado los "casos", como el de Rosas, que le permitieron identificar los resortes psicosociales de la conducción caudillista, la reflexión psicosocial que Carlos Augusto Bunge despliega en torno del líder está irrigada por materiales históricos.

\section{EL JEFE PENSADO COMO "CACIQUE"}

Entendido como un elemento central de la constelación de prácticas que constituye la "política criolla" (Bunge, 1926: 52) ${ }^{32}$, el 
De Prácticas y discursos

Universidad Nacional del Nordeste

Centro de Estudios Sociales

Año 9, Número 14, 2020, Octubre

ISSN 2250-6942

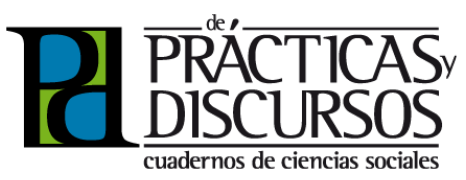

\footnotetext{
${ }^{33} \mathrm{Al}$ igual que el autor francés, la concepción de raza que impregna la obra de Bunge incluye tanto determinaciones físicas como psíquicas, funcionando como un "atavismo" que se impone tarde o temprano (Talak, 1999). El sometimiento a las necesidades impiadosas del determinismo biológico, psicológico y social explica el pesimismo con el que el autor se refiere a la política (Terán, 1998).
}

"cacique" es la figura histórica en torno a la que discurre la problematización bungeana de la jefatura.

Según el diccionario de la Real Academia Española, en la actualidad el mismo designa tanto al "jefe de una tribu de América Central y del Sur", como a un gobernante "personalista" y "autoritario"; esto es, tiene una doble significación, una cuyo valor es "neutro" y otra que, en cambio, trasunta una valoración negativa. Portavoz de un discurso biologista racialista/racista que estigmatizaba a los "indios" y a los "negros" y que compartía con otros intelectuales argentinos de la época (Grondona, 2019), Bunge declina, en su libro, la segunda significación de la primera. Era del "jefe de la tribu" de donde los "caciques" o "caudillos" de las nóveles repúblicas hispanoamericanas habian heredado los rasgos negativos que los caracterizaban. De alli que la jefatura de esto últimos solo pudiera entenderse a partir del conocimiento histórico-cultural del "carácter argentino", objeto que, al igual que Le Bon, el autor aborda desde una perspectiva racialista (Del Brutto, 2000) ${ }^{33}$. Pero si el autor francés encuentra en el pasado el punto de apoyo para el ejercicio del tipo de liderazgo despótico por el que se inclina, por el contrario Bunge responsabiliza al pasado colonial hispánico y precolonial del perfil de conductor hacia el que apunta las armas de su crítica.

Según tal matriz bio-psico-social de interpretación en la que abrevan varias otras lecturas del caudillismo contemporáneas a la del autor de Nuestra América, el mismo establece un correlato entre la "psicología colectiva", entendida en un sentido etnocultural, y las "formas de la vida política".

Si bien cortada sobre el tipo de jefatura indígena de la "antigua América" (Bunge, 1926: 260), el "cacique" es una figura híbrida en la que confluyen los rasgos caracterológicos que el mismo atribuía tanto a la "raza indígena" como a las "diversas razas" de las que descendia la "raza hispana".

Mientras la autoridad de los distintos perfiles de conductores que hasta ahora consideramos procedia, sea de la capacidad para esclarecer, determinar y satisfacer los deseos y necesidades de los conducidos (Tarde), de la tradición (Le Bon) o de las ilusiones y aspiraciones plebeyas de las masas (Ramos Mejía), la autoridad del cacique se deriva, exclusivamente, de la camaradería, complicidad o connivencia que lo liga, de manera individual, con cada uno de los conducidos; incluyendo a aquellos que conforman el círculo de subalternos que lo asisten en el ejercicio del mando. 
De Prácticas y discursos

Universidad Nacional del Nordeste

Centro de Estudios Sociales

Año 9, Número 14, 2020, Octubre

ISSN 2250-6942
¿ Inventores, apóstoles, ídolos o caciques? Una aproximación a la problematización del "Iíder" en los albores del pensamiento sociológico y psicosocial

Inventors, apostles, idols or chieftains? An approach to the problematization of the "leader" at the dawn of sociological and psycho-social thought

Así, mientras la crítica ramosmejiana a la simulación consistía en demostrar que la misma encubria la falta de talento, lo que a Bunge (1926: 296) le obsesionaba era la "falta de ideales". En ese sentido, los caciques no eran más que los exponentes de la crisis moral que embriagaba a la sociedad de su época; cuyas causas se adentraban, en la visión del autor, en los atavismos de la raza. Nostálgico, constituía a los "patriotas" que habian protagonizado, según la interpretación aceptada, la gesta de la independencia argentina, en una suerte de reserva moral de la nación. Tal "culto a los héroes" se explica proviniendo de un autor que, al igual que Ramos Mejía, encontraba en la educación un medio para contagiar a los inmigrantes de patriotismo.

Enfatizando la dimensión personalista del cacicato, denuncia, por espurio, el liderazgo que en lugar de fundarse en la capacidad del jefe, la razonabilidad o verdad de ciertas ideas, se ancla, exclusivamente, en la popularidad, conseguida sobre la base de "vergonzosas complacencias" (Bunge, 1926: 239).

La efigie de líder que la psicología social de Bunge proyecta no es ni la de un apóstol ni la de un ídolo, sino la de un "amigo", alguien de quien los conducidos esperan un tipo de solidaridad que, sin estar basada en lazos de parentesco, se asemeja, no obstante, a la solidaridad familiar. Ello se explica porque, según la genealogía que traza el autor, el vínculo cacical procede de la relación privada, de carácter religioso, que el "padrino" de bautismo de un niño mantenía con sus padres. Siendo que de acuerdo a las antiguas costumbres españolas, el "padrino" oficiaba de "padre espiritual", la elección recaía sobre personas que los padres consideraban tenían condiciones para protegerlos y conducirlos. De ese modo, se colocaban voluntariamente bajo la órbita de influencia de un cacique efectivo o en gestación (Bunge, 1926: 274). En esa dirección, el autor llama la atención respecto de la enorme cantidad de vínculos de compadrazgo de los que los caudillos participaban, en calidad, claro está, de padrinos.

A esa significación religioso-familiar del término "compadre", existente desde los tiempos de la colonia, se sobreimprimieron, luego de la emancipación, otras de carácter político-cultural, que dan cuenta de la variación de los contextos históricos en el que el mismo se utilizó y de los usos peyorativos que adquirieron los términos cacique y caudillo. Así, si como parte del vocabulario político, compadre se vuelve equiparable, al comenzar las luchas por la organización política, a "amigo, compañero, aliado", "al 
De Prácticas y discursos

Universidad Nacional del Nordeste

Centro de Estudios Sociales

Año 9, Número 14, 2020, Octubre

ISSN 2250-6942

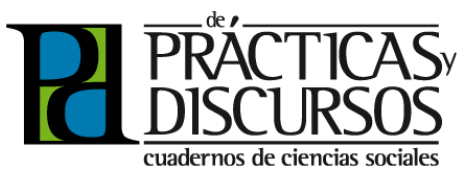

asumir el caciquismo criollo formas menos ingenuas en las ciudades (...) la palabra 'compadre' (...) Ilegó a significar gaucho, campesino, rústico, chusco, paisano" (Bunge, 1926: 275).

Derivada del análisis de experiencias históricas de liderazgo político, la noción de líder que surge de Nuestra América es la de un "animal político" cuya única aspiración consiste en acceder y mantenerse en el poder, "no para conquistar los laureles de la historia sino por el placer de mandar" (Bunge, 1926: 248).

Al igual que otros de los perfiles de líderes de los que nos ocupamos aquí, el "cacique gaucho" cultiva la mentira en política en una modalidad específicamente mestiza. Aprovechando el talento para contar historias que había heredado de los caciques de las tribus indígenas y de sus antepasados hispánicos "macaneaba", apelando, entre otros recursos, a frases "huecas y sonoras como campanas" (Bunge, 1926: 248) que extraía de la retórica democrático-republicana.

Es que el vínculo que tal clase de dirigentes traban con las masas se despliega en el registro de la simulación, temática a la que, como vimos en el apartado anterior, Ramos Mejía se referiría largamente solo un año después. Así, por ejemplo, Juan Manuel de Rosas, arquetipo del cacique gaucho, utiliza de manera recurrente tal recurso porque, al igual que otros caudillos, si bien no procede de las masas, con las cuales se "camufla", detenta un tipo de superioridad que, siendo "intermedia" (ni demasiado bárbara ni demasiado culta) resulta, en opinión del autor, "concordante" con los deseos y expectativas de las mismas.

Ahora bien, la mala fe del cacique no flota en el aire, sino que encuentra en la "pereza criolla", rasgo distintivo del carácter nacional, su punto de apoyo colectivo. Si el cacique orilla las dificultades de la realidad, inventando, a gusto de cada uno, el mundo en que se vive; la ciudadanía que lo sigue deja de fingir para "rehuir toda responsabilidad, todo trabajo" (Del Brutto, 2000: 227). Sujeto "activo" entre "indolentes" (Bunge, 1926: 239), el caudillo se impone sobre la base de relaciones de compadrazgos y cohecho porque, con relación a la cosa pública, el pueblo delega en él toda iniciativa y responsabilidad.

\section{REFLEXIONES FINALES}

A lo largo del artículo buceamos en la historia del pensamiento sociológico y psicosocial con la finalidad de recuperar y poner 
De Prácticas y discursos

Universidad Nacional del Nordeste

Centro de Estudios Sociales

Año 9, Número 14, 2020, Octubre

ISSN 2250-6942
¿ Inventores, apóstoles, ídolos o caciques? Una aproximación a la problematización del "Iíder" en los albores del pensamiento sociológico y psicosocial

Inventors, apostles, idols or chieftains? An approach to the problematization of the "leader" at the dawn of sociological and psycho-social thought

en diálogo las reflexiones que el problema de la jefatura suscitó, entre fines del siglo XIX y los primeros años del siglo XX, en un conjunto de autores franceses $y$ argentinos.

Ello supuso una aproximación novedosa a un corpus de textos que, si bien se retrotraen muy atrás en el tiempo, articulan cuestiones que están vigentes en la actualidad. Novedosa porque, dejando de lado el ensayo de Gustave Le Bon, que se considera precursor del arte (moderno) de la propaganda política (Moscovici, 1985), la relectura que efectuamos de los textos de Tarde, Ramos Mejía y Bunge los habilita a participar de una conversación de la que, hasta ahora, habian permanecido al margen.

Así, si bien en los últimos años los escritos de Gabriel Tarde han sido objeto de numerosas relecturas (Lazzarato, 1999, 2018; Latour, 2002, 2009, entre otras), las mismas no han puesto énfasis en el problema político de la "conducción" y menos aún en el modo en que el autor pensó la figura del "jefe".

Ciertamente, las reflexiones que Ramos Mejía y Bunge dedicaron a la temática de la jefatura no han pasado desapercibidas a los autores que en las últimas décadas revisitaron sus obras (Buchbinder, 1998; Svampa, 1998). Sin embargo, esa recuperación se ha dado en el contexto de los debates historiográficos y sociológicos acerca del "caudillismo hispanoamericano"; es decir, en el marco de una conversación que enfoca solo una de las salientes analiticas de una problemática que es mucho más amplia y compleja. Entre los saldos de la comparación que aquí ensayamos, corresponde anotar que los aportes que los autores argentinos hicieron a la problematización "moderna" del liderazgo se distinguen de aquellos de sus pares franceses porque se despliegan en una perspectiva sociohistórica, y dejan ver las marcas del contexto nacional y de la coyuntura en la que se escribieron. Por el contrario, en Las leyes de la imitación la discusión acerca del rol que en vistas a la configuración y transformación de lo social desempeñan los "inventores" y los "apóstoles de lo nuevo" se plantea en un registro teórico-abstracto. Por su parte, aunque en Psicología de las masas la noción de jefe no deja de movilizarse para describir ciertos fenómenos de la coyuntura francesa, la figura del "apóstol del orden" sobre la que el autor discurre se prescribe como solución frente a los problemas sociopolíticos que padecen (en virtud del juego de los determinismos raciales) los "pueblos latinos" entendidos como un todo.

Es que, a excepción de Tarde, cuyas elaboraciones permiten pen- 
De Prácticas y discursos

Universidad Nacional del Nordeste

Centro de Estudios Sociales

Año 9, Número 14, 2020, Octubre

ISSN 2250-6942

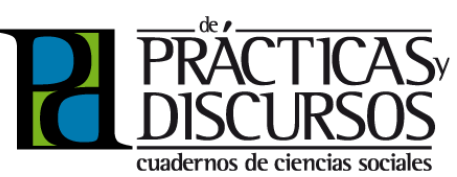

${ }^{34}$ Es preciso destacar que ya Josefina Ludmer (2017: 136) hizo de la "representación" la clave interpretativa de Los simuladores del talento. sar diferentes clases de liderazgo, los trabajos de los demás autores enfocan, específicamente, la cuestión de la jefatura política. Escritos en una época en la que no solo el mito del "gran hombre" sino la creencia en la "unidad" y "autonomía" del yo eran severamente impugnados, y en la que la idea misma de superioridad estaba en discusión, los textos que consideramos reflexionan en torno a las tareas de conducción que, en la era de las "masas" y los "públicos", ciertos individuos estaban llamados a cumplir. Así, mientras Le Bon atribuye a los líderes una función ordenancista, en una sociedad atravesada por conflictos de clase que "el jefe" está llamado a reconstituir racialmente; las reflexiones, ciertamente diversas, que Ramos Mejía y Bunge propusieron acerca de los líderes, están atravesadas por la cuestión de la "representación ${ }^{34 "}$ de las multitudes urbanas conformadas por trabajadores e inmigrantes a partir de las cuales "urgía" edificar la nación. Por su parte, mientras Tarde deposita sobre los genuinos inventores la misión de evitar la muerte por "entumecimiento" de "lo social", la tarea misional que desempeñan aquellos que se ocupan de divulgar los descubrimientos e invenciones realizados por otros, apunta a generar la uniformidad que, en las sociedades postradicionales, es condición para el florecimiento de individualidades más sofisticadas.

Es preciso destacar que en los cuatro focos de la problematización analizada, la actuación del jefe viene a suplir una "falta" que se inscribe, indefectiblemente, del lado de "los muchos". En Ramos Mejía la misma se define en términos de la ausencia de facultades de relación que caracteriza a las multitudes, y que el lider tiende a remedar porque, al funcionar como imagen del yo (una imagen ideal, además) permite que cada individuo conozca lo que tiene en común con los demás, dando fijeza y estabilidad a algo que de otro modo es puro movimiento.

Por su parte, Tarde, Le Bon y Bunge convergen en pensar la falta en términos de una "insuficiente laboriosidad". Asi, mientras para el autor de Psicología de las masas el líder es aquel "individuo de carácter" que frente al insuficiente o deficitario desarrollo del autocontrol viene a poner orden en personalidades que de otro modo se encaminan inexorablemente a la decadencia; el "cacique" al que se refirió Bunge se ocupa de la dirección de los asuntos comunes frente a una gran mayoría de "perezosos" y "apáticos" que le dejan hacer. También Tarde, autor que lejos está de concebir el carácter ora individual, ora colectivo, en términos sustancialistas, el "inven- 
De Prácticas y discursos

Universidad Nacional del Nordeste

Centro de Estudios Sociales

Año 9, Número 14, 2020, Octubre

ISSN 2250-6942
¿ Inventores, apóstoles, ídolos o caciques? Una aproximación a la problematización del "Iíder" en los albores del pensamiento sociológico y psicosocial

Inventors, apostles, idols or chieftains? An approach to the problematization of the "leader" at the dawn of sociological and psycho-social thought

tor" se distingue del grueso de los hombres, porque venciendo la tracción a la reproducción que surge de la dinámica misma de la vida social, se adentra en la aventura de crear. En contraposición a esas posturas, en su libro de 1899 Ramos Mejía reconoce a ciertas configuraciones históricas de las multitudes argentinas un grado importante de creatividad y dinamismo, el cual se expresa en el papel que, en la interpretación del autor, las mismas desempeñaron en el proceso de emancipación.

De la mano de las elaboraciones dedicadas a escrutar los resortes psicológicos y éticos de la conducción, los autores plantean una serie de ideas relativas a las formas que asumen las jerarquias en las sociedades "igualitarias" modernas.

Así, las elaboraciones de Le Bon nos proponen la idea de un tejido social estriado por relaciones de jerarquía fija y racialmente determinada, que se constituyen a partir de la diferente magnitud que revisten las voluntades de los hombres que lo conforman. En su visión, el líder es un hombre de carácter fuerte capaz de autogobernarse y de imponer a las lábiles voluntades de los sujetos de las masas latinas, un mito que las aglutine y apacigüe. Sin arraigo necesario (como en el caso de Le Bon) en determinaciones etnoraciales, sino fundada en la incidencia "accidental" que tienen, en el devenir de las sociedades, ciertos hombres geniales, la distinción entre "inventores" e "imitadores" delinea, en la teoría social tardeana, una jerarquía, flexible, móvil y reversible, pero jerarquia al fin.

Vinculada, no menos que los escritos de los autores franceses, a la pregunta por las formas que asumian las jerarquias en las sociedades modernas, la tematización de la figura del caudillo está atravesada, en los trabajos de Ramos Mejía y de Bunge, por la atención que confirieron a la problemática más general de la simulación. Ciertamente, el uso de esta última categoría, que hace del meneur un falsificador, involucra una mirada crítica respecto de la superioridad entendida como popularidad. Sin embargo, la maniobra falsificadora es necesaria para que se produzca la alquimia de la "representación". Al prestarse al trabajo deformante de la mentalidad colectiva, que "lee sobre aquel fragmento de hombre, sin un solo trazo que autorice la ilusión, las calidades y aptitudes que necesita utilizar" (1904: 53), los caudillos encarnan, genuinamente, las "voluntades y apetitos de determinadas fracciones, que le dan ponderación social" (Ramos Mejía, 1904: 57); fracciones de las cuales, en la opinión de Bunge, no estaban tan distantes. 
De Prácticas y discursos

Universidad Nacional del Nordeste

Centro de Estudios Sociales

Año 9, Número 14, 2020, Octubre

ISSN 2250-6942

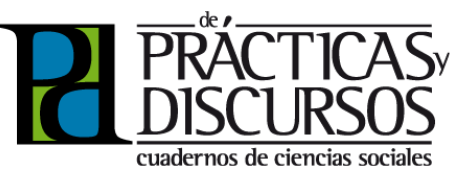

Para concluir, consideramos que el esfuerzo que aquí realizamos, al delinear un conjunto de dimensiones analíticas y movilizarlas para estudiar la problematización psicosociológica del liderazgo, tal como la misma se desarrolló, simultáneamente, en distintos contextos nacionales, puede coadyuvar tanto a la producción de historias del pensamiento sociológico, politológico y psicosocial, como a la realización de investigación en teoría, esto es, de indagaciones de carácter "meta" que procuren esclarecer, sistematizar y criticar los modos en que desde las ciencias sociales y las humanidades se ha pensado tal cuestión.

Por otro lado, retomando las observaciones que planteamos en la introducción acerca de las formas en que parece articularse, en nuestras culturas, el pensamiento acerca del liderazgo, los desarrollos de corte sociohistórico que aquí efectuamos pueden servir como disparadores de investigaciones que tengan por objeto estudiar las transformaciones en los modos de problematización de tal cuestión.

Así, entre las figuras contemporáneas del "director de proyectos" y del "jefe de equipos" que surgen del campo de marketing, de cuerpos de pensamiento y prácticas ligados al desarrollo personal y la espiritualidad, no menos que del ámbito de la política, y los términos que enmarcan la reflexión psicosociológica en torno del jefe que se desarrolló entre fines del siglo XIX y los primeros años del siglo $X X$, existen distancias y proximidades que es necesario calibrar, si deseamos comprender, en su singularidad, nuestra historia, tanto "pasada" como "presente".

\section{BIBLIOGRAFÍA}

AGUILAR, P. (2013). Domesticidad e intervención: el "hogar" en los debates de la cuestión social (1890-1940). Debate Público. Reflexión de Trabajo Social, 6, 43-58.

APFELBAUM, E. (1988). Les enjeux d'une histoire de la psychologie sociale. Revue de synthese, 3-4, 489-510.

BIALAKOWSKY, A. (2018). Investigar teoría sociológica del Sur y del Norte: la propuesta del abordaje simultáneo. Perfiles Latinoamericanos, 52, 1-19.

BIALAKOWSKY, A. Y BLANCO, A. (2019). Multitudes y es- 
De Prácticas y discursos

Universidad Nacional del Nordeste

Centro de Estudios Sociales

Año 9, Número 14, 2020, octubre

ISSN 2250-6942
¿ Inventores, apóstoles, ídolos o caciques? Una aproximación a la problematización del "Iíder" en los albores del pensamiento sociológico y psicosocial

Inventors, apostles, idols or chieftains? An approach to the problematization of the "leader" at the dawn of sociological and psycho-social thought

tilos fundacionales. En De Marinis, P. (coord.) Exploraciones en teoría social. Ensayos de imaginación metodológica (pp. 89-150). Buenos Aires: Clacso-IIGG.

BLANCO, A. (2016). De la monadología a la microsociología. Rastreando supuestos ontológicos en los textos de Gabriel Tarde. En Borisonik, H. et al. (comps.) Artículos seleccionados de las VIII Jornadas de jóvenes investigadores del IIGG (pp. 19-38). Buenos Aires: Clacso.

BLANCO, A. Y HAIDAR, V. (2020). Las transformaciones en la conducción. Los aportes de Gabriel Tarde al pensamiento político. Revista Studia Politicae. En prensa.

BLONDEL, J. Y THIÉBAULT, J.L. (2010). Political leadership, parties and citizens: the personalization of leadership. New York: Routledge.

BODEI, R. (2006). Destinos Personales. Buenos Aires: El cuenco de Plata.

BORCH, C. (2012). The Politics of Crowds: An Alternative History of Sociology. Cambridge: Cambridge University Press.

(2019). Introduction. The imitative, contagious and suggestible roots of modern society. Toward a mimetic foundation of social theory. En Borch, C. (ed.) Imitation, contagion, suggestion (pp. 3-34). London \& New York: Routledge.

BOTANA, N. (1994). El orden conservador. La política argentina entre 1880 y 1916. Buenos Aires: Sudamericana.

BUCHBINDER, P. (1998). Caudillos y caudillismo: una perspectiva historiográfica. En Goldman, N. y Salvatore, R. (comps.) Caudillismos rioplatenses. Nuevas miradas a un viejo problema (pp. 31-50). Buenos Aires: Eudeba.

BUNGE, C.0. (1926). Nuestra América. Madrid: Espasa-Calpe. (Versión original 1903).

D'ALESSANDRO, M. (2004). ¿Qué es la personalización de la política? Algunos hallazgos en los medios gráficos, 1983-1995. Revista Argentina de Ciencia Política, 7/8, 73-94. 
DEL BRUTTO, B.A. (2000). Raza y carácter: algunos apuntes sobre la sociología de las mentalidades. En González, H. (comp.) Historia crítica de la sociología argentina. Buenos Aires: Colihue.

DEVOTO, F. Y PAGANO, N. (2009). Historia de la historiografía argentina. Buenos Aires: Sudamericana.

DONZELOT, J. (2007). La invención de lo social. Ensayo sobre la declinación de las pasiones políticas. Buenos Aires: Nueva Visión. (Versión original 1984)

GEROULANOS, S. (2014). The Plastic Self and the Prescription of Psychology: Ethnopsychology, Crowd Psychology, and Psychotechnics, 1890-1920. Republics of Letters: A Journal for the Study of Knowledge, Politics, and the Arts, 3 (2), 1-31. Disponible en: http://arcade.stanford.edu/rofl/plastic-self-andprescription-psychology.

GONZÁLEZ, H. (2000). Ciencia, burla y ontología revolucionaria en el pensamiento argentino del siglo veinte. INTI, 52/53, 371-394.

GRONDONA, A. (2019). Cuestión racial y sociología argentina: Sarmiento, Ayarragaray, Bunge e Ingenieros frente a Germani. Aportes en clave genealógica de cara al Sur. De Prácticas y discursos, 12. Disponible en: http://ppct.caicyt.gov.ar/index.php/depracticasydiscursos/article/view/16651/45454575768850

LE BON, G. (1912). La psicología política y la defensa social. Madrid: Librería Gutemberg.

(1924). L'evolution de l'Europe vers des formes diverses de dictature. Les Annales politiques et littéraires, 2 de marzo, 231-232.

(1927). L'évolution actuelle du monde: illusions et réalités. Paris: Flammarion.

(1986). Psicología de las masas. Madrid: Morata. (Versión original 1895).

Lazzarato, M. (1999). Postface. Gabriel Tarde: un vitalisme politique. En Tarde, G. (ed.) Monadologie et sociologie (pp. 103150). Paris: Instituto Synthélabo. 
De Prácticas y discursos

Universidad Nacional del Nordeste

Centro de Estudios Sociales

Año 9, Número 14, 2020, octubre

ISSN 2250-6942
¿ Inventores, apóstoles, ídolos o caciques? Una aproximación a la problematización del "líder" en los albores del pensamiento sociológico y psicosocial

Inventors, apostles, idols or chieftains? An approach to the problematization of the "leader" at the dawn of sociological and psycho-social thought

(2018). Potencias de la invención. Buenos Aires: Cactus.

LUDMER, J. (2017). El cuerpo del delito. Buenos Aires: Eterna Cadencia.

HAIDAR, V. (2008). Trabajadores en riesgo. Una sociología histórica de la biopolítica del trabajo asalariado en la Argentina (1890-1915). Buenos Aires: Prometeo.

(2019). ¿Autoritarismo al interior del liberalismo? Entre los aportes de los Governmentality Studies y las posibilidades abiertas por la Historia del Presente. En Avellaneda, A. y Vega, G. (dir.) Conductas que importan. Variantes de análisis de los Estudios en Gubernamentalidad (pp. 77-104). Corrientes: Eudene.

(2020). La problematización del liderazgo político en los albores del pensamiento sociológico argentino: las lecturas de Domingo F. Sarmiento, Ernesto Quesada y José María Ramos Mejía acerca del fenómeno rosista. Cuestiones de Sociología, 21. Disponible en: https:// doi.org/10.24215/23468904e087.

LATOUR, B. (2002). Gabriel Tarde and the End of the social. Disponible en: http://bruno-latour.fr/articles/082.html.

(2008). Reensamblar lo social. Una introducción a la teoría del actor-red. Buenos Aires: Manantial.

MAILHE, A. (2016). Estudio introductorio. En Mailhe, A. (ed). Archivos de Psiquiatría y Criminología (1902-1913) (9-121). La Plata: Universidad Nacional de La Plata.

Moscovicl, S. (1985). La era de las multitudes. México: FCE.

OSBORNE, T. Y ROSE, N. (1997). In the name of society, or three theses on the history of social thought. History of the human sciences, 10 (3), 87-104.

RAMOS MEJÍA, J.M. (1899). Las multitudes argentinas. Buenos Aires: Marymar.

(1904). Los simuladores del talento. Buenos Aires: Felix Lajouane Eds. 
SVAMPA, M. (1998). La dialéctica entre lo nuevo y lo viejo: sobre los usos y nociones del caudillismo en la Argentina durante el siglo XIX. En N. Goldman y R. Salvatore (eds.) Caudillismos rioplatenses. Nuevas miradas a un viejo problema (pp. 51-82). Buenos Aires: Eudeba.

TALAK, A.M. (1999). La psicología social del positivismo. La articulación de discursos psicológicos y discursos ético-políticos en el pensamiento positivista sobre lo social. Ponencia presentada en las VI Jornadas de Investigación en Psicología, UBA, 2 y 3 de diciembre.

TARDE, G. (1972). La philosophie pénale. Paris: Éditions Cujas. (Versión original 1890).

(2011). Las leyes de la imitación. Madrid: Centro de Investigaciones sociológicas-Agencia Estatal del Boletín Oficial del Estado. (Versión original: 1890).

(2013). Las leyes sociales. Barcelona: Gedisa (Versión original: 1898).

(2015a). Los crimenes de las muchedumbres. En Ensayos Sociológicos, vol. 1 (87-118). Buenos Aires: Prometeo. (Versión original 1892).

(2015b). Muchedumbres y sectas desde el punto de vista criminal. En Ensayos Sociológicos, vol. 1 (41-86). Buenos Aires: Prometeo. (Versión original 1893).

TERÁN, 0. (1998). Carlos Octavio Bunge: entre el científico y el político, Prismas, № 2, 95-110.

(2010) Historia de las ideas en la Argentina. Diez lecciones iniciales, 1810-1980. Buenos Aires: Siglo XXI.

Van Ginneken, J. (1992). Crowds, Psychology \& Politics, 1871 1899. Cambridge: Cambridge University Press.

VON STECHER, P. (2014). Estudios cientificos y estética literaria. Un análisis del discurso médico-académico en la Argentina (1890-1910). Acta Poetica, 35 (1), 119-147.

ZIMMERMANN, E. (1995). Los liberales reformistas. Buenos Aires: Sudamericana. 